\title{
Comparative ANALYSIS OF Single-CORE AND MULTI-CORE SYSTEMS
}

\author{
Ogundairo Johnson $^{1}$ and Omosehinmi Dinyo ${ }^{2}$ \\ ${ }^{1}$ Department of Information Technology, National Open University of Nigeria (NOUN), \\ Enugu Campus, Enugu, Nigeria \\ ${ }^{2}$ Department of Physics, Federal University of Technology, Akure, Nigeria
}

\begin{abstract}
Overall performance of computer systems are better investigated and evaluated when its various components are considered, components such as the hardware, software and firmware. The comparative analysis of single-core and multi-core systems was carried out using Intel Pentium G640T 2.4GHz dualcore, Intel Pentium IV 2.4GHz single-core and Intel Pentium IV 2.8GHz single-core systems. The approach method was using hi-tech benchmarking and stress testing software(s) to examine systems' CPU and RAM for performance and stability. In all the tests, the components of dual-core had better rating when compared with single-core components; GFLOP result, and execution time for various processes rank G640T $2.4 \mathrm{GHz}$ dual-core above Pentium IV 2.4GHz and $2.8 \mathrm{GHz}$ single-core respectively.
\end{abstract}

\section{KEYWORDS}

FLOP, ILP, TLP, Multi-core, Single-core, Novabench \& Linpack.

\section{INTRODUCTION}

Operational advancements of microprocessors over the years were primarily due to speed (frequency) and parallelism increment [1] [2] [3] [13]. The addition of more transistors has led to other ways and/or techniques of increasing parallelism and improving performance [13]. Subsequently, architects then sought to increase parallelism by executing multiple instructions simultaneously (instruction-level parallelism or ILP) through pipelining techniques and superscalar architectures and to reduce the latency of accessing memory with ever larger on-chip caches. Microprocessors further increased ILP by implementing out-of-order execution engines that completed useful work instead of stalling on data and control dependencies [4]. It is now obvious that ILP increment, due to energy, heat and wire delay issues can no longer provide performance improvements that track Moore's Law [5]. Therefore, vendors have shifted attention to exploring thread-level parallelism (TLP) by designing chips with multiple processors, otherwise known as Multi-core or Chip Multiprocessors (CMPs). The implementation of high level TLP on multi-core(s) will continue to provide performance improvement while dealing with the traditional technology issues faced by single-core performance [4]. These new designs are referred to as multi-core processors because it has minimum of two execution cores with distinct execution pipelines, functional units and usually one level of private cache [24].

A Multi-core processor consists of two or more cores on a single die [6] [9] [26]. The cores of CMPs are essential components usually computation units and caches [6]. The individual cores on a multi-core processor don't necessarily run as fast as the highest performing single-core processors, but they improve overall performance by handling more workloads in parallel [7] [8]. 
The performance of single-core and multi-core processors is better understood by observing how the two execute programs [9]. Single-core processors running multiple programs would assign different time slices for these programs; if one of the processes is taking longer time to complete then all the rest of the processes start lagging behind [9]. However, in the case of multi-core processors if you have multiple tasks that can be run in parallel at the same time, each of them will be executed by a separate core in parallel thus boosting the performance [8].

It is a general belief that multi-core processor, similar to many-core processor, has several advantages over single-core processor. First, multi-core processors have the advantage of shorter wiring which reduced the delay among cores instead of going off-chip [11]. Second, the issue of width and instruction window size incur linear increment on the chip area of multi-core processors whereas a quadratic increment is incurred in single-core processor design [10]. Third, the design-partition of multi-core processors are configured in such a way that idle cores can be powered down or powered up as and when needed by the application contributing to overall power dissipation savings [9]. The multiple cores inside the chip are not clocked at a higher frequency, however, their high-level parallelism potential is what responsible for its eventual overall performance making them more energy efficient and low power cores [8] [9]; whereas power consumption has been one of the critical concerns in single-core processors [11].
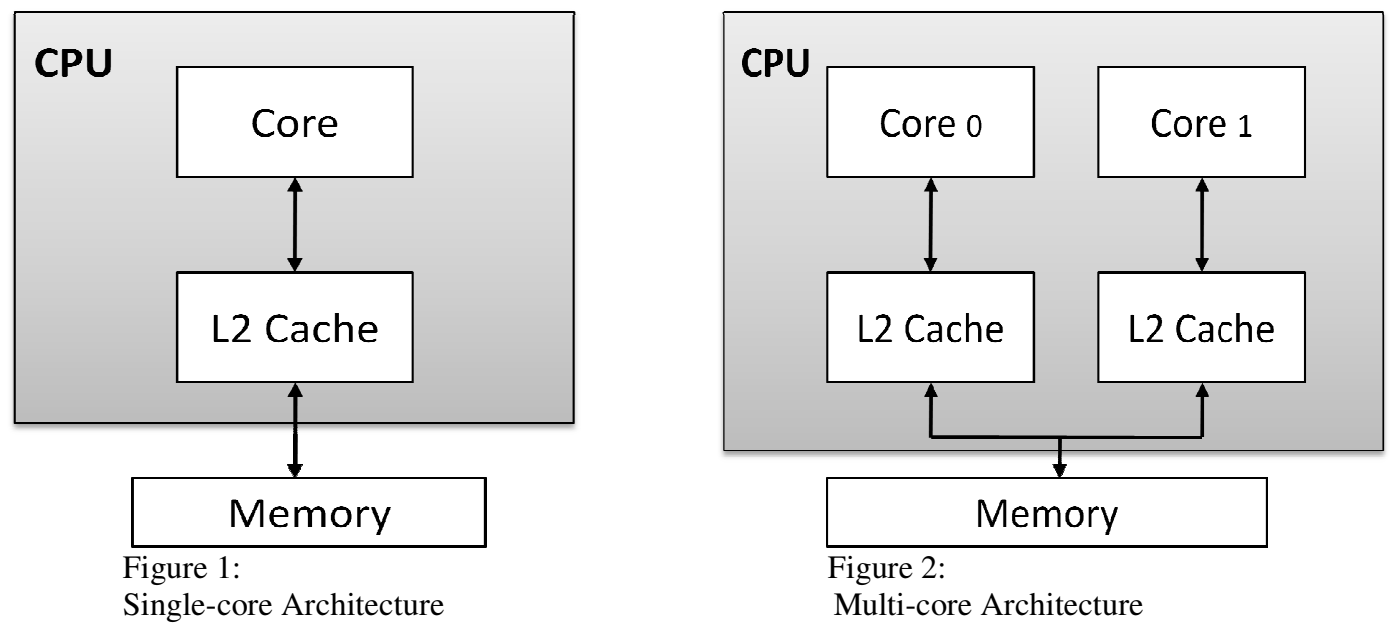

Figure 1 and 2 illustrates the architecture of a processing system with one core (single-core) and two cores (multi-core) respectively. A core in this context includes the following: instruction processing pipelines (integer and floating-point), instruction execution units, and the L1 instruction and data caches. Recently manufactured general-purpose computers appear like the dual-core (i.e. multi-core) system in that they have two separate but identical cores [12]. In some processing systems such as Intel Pentium-D and Opteron, each core has its own private L2 cache, while in others- Intel Core Duo, the L2 cache is shared between different cores. In multi-core(s), the option of a shared versus non-shared L2 cache have impacts on the performance of the system and a shared cache can be a possible source of vulnerability to Denial of Service (DoS) attacks because the memory system is disproportionately shared among multiple cores [12].

Despite the many advantages that multi-core processors have over single-core processors, there are a few major challenges the technology is facing [9]. Some software programs run slower on multi-core processors when compared to single-core processors. It has been correctly identified that increasing the cores of a processing system don't automatically get applications on multi-core systems to run faster [1]. Also, on-chip interconnects are becoming a critical logjam in meeting performance of multi-core chips [14]. With increasing number of cores comes along the huge 
interconnect delays (wire delays) when data has to be moved across the multi-core chip from memories in particular [15]. The performance-effectiveness of a processor is a function of how fast a CPU can fetch data rather than how fast it can operate on it to avoid data starvation scenario [16].

The capability of multi-core processors to run applications more efficiently than single-core processors has given computer users the ability to keep working, at the same time running the most processor intensive tasks in the background [25]. A process with multiple threads has as many flows of controls as there are threads [26]. Each of these threads execute its own sequence of instructions independently and concurrently [26]. A process with multiple threads is called multithreaded [17] [26]. Thus the multi-cores improve multithreaded throughput, and delivers the advantages of parallel computing to properly thread mainstream applications [18]. Applications such as those use for wireless networking, computer vision, image processing, and multimedia possess great amount of functional and data parallelism, which can be exploited through a multicore (System-on-Chip) [19] [25]. But for systems where single threaded applications dominate, multi-core systems offer very limited benefits [20]. It is on this note comparative analysis of single-core and multi-core system is being studied.

\section{Materials AND Methods}

Many researches have approached the comparative analysis of single-core and multi-core systems using diverse techniques, mostly as it concerns the area being studied. This involves the use of compiler or software tools like SPEC2006 to run test on certain components of the systemprocessor and RAM to see how it responds under specific or general condition per time. FLOP is commonly examined [21]. However, since FLOPs measure only raw execution rate, it can not be regarded as the best measurement of true speed. The true processor speed of a system is dependant on many other factors which include- pipeline length, register size, response time, cache size, cache latency, cache associativity, number of pipelines, instruction sets, number of registers, etc [28].

In this work, the comparative analysis of single-core and multi-core systems was approached by exploring firmware testing. This is done by using hi-tech software(s) to examine systems' CPU and RAM for performance and stability. The software(s) include: Intelburn Test - Stress testing software; Novabenchmark - Benchmarking software; and Performance Test - Benchmarking software. The stress testing software aims to test stability by trying to force a system to fail; and benchmarking aims to measure and assess the maximum performance possible at a given task or function [27]. Thereafter, a 33.3Gigabyte file-folder of 327 folders and 3480 files comprising videos, application software(s) and documents of different formats were copied from an external SATA-Hard Disk Drive, HDD to systems' internal HDD; features such as Number of processes, CPU usage, and Physical memory were observed and data collected for both the single-core and multi-core systems. The time taken to complete the transfer was however put under critical examination. Driverpack solutions and CPU-Z software tools were used to check for systems' $\mathrm{CPU}$ frequency, $\mathrm{CPU}$ temperature and core voltage. Apart from the information provided by these tools, it also envisages how multitasking affects the transfer process and its overall impart on the systems. 
International Journal of Computer Science \& Information Technology (IJCSIT) Vol 7, No 6, December 2015

Table 1. Configuration of the Systems Under Test (SUT)

\begin{tabular}{|c|c|c|c|}
\hline & $\begin{array}{l}\text { HP COMPAQ } \\
\text { DESKTOP PC, } \\
\text { INTEL PENTIUM } \\
\text { SINGLE-CORE } \\
\text { SYSTEM }\end{array}$ & $\begin{array}{l}\text { HP COMPAQ } \\
\text { DESKTOP PC, } \\
\text { INTEL PENTIUM } \\
\text { SINGLE-CORE } \\
\text { SYSTEM }\end{array}$ & $\begin{array}{l}\text { HP DESKTOP PC, } \\
\text { INTEL PENTIUM } \\
\text { DUAL-CORE } \\
\text { SYSTEM }\end{array}$ \\
\hline \multicolumn{4}{|l|}{ CPU } \\
\hline Vendor & GenuineIntel & GenuineIntel & GenuineIntel \\
\hline Name & Intel Pentium 4 & Intel Pentium 4 & Intel Pentium G640T \\
\hline $\begin{array}{l}\text { Core Frequency } \\
(\mathrm{GHz})\end{array}$ & $2.4 \mathrm{GHz}$ & $2.8 \mathrm{GHz}$ & $2.4 \mathrm{GHz}$ \\
\hline Number of CPU & 1 & 1 & 1 \\
\hline Number of cores & 1 & 1 & 2 \\
\hline Number of threads & 1 & 2 & 2 \\
\hline Processor type & $\begin{array}{c}\text { Intel Pentium } 4 \\
\text { Single-core processor }\end{array}$ & $\begin{array}{c}\text { Intel Pentium } 4 \\
\text { Single-core processor }\end{array}$ & $\begin{array}{l}\text { Intel Pentium G640T } \\
\text { Dual-core processor }\end{array}$ \\
\hline \multicolumn{4}{|c|}{ 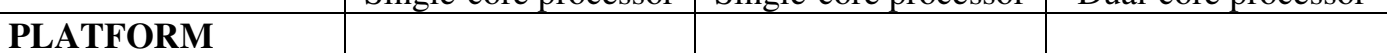 } \\
\hline $\begin{array}{l}\text { BIOS Name \& } \\
\text { Version }\end{array}$ & BIOS F.3.4 & BIOS F.3.4 & BIOS AMI 7.12 \\
\hline BIOS Setting & Default & Default & Default \\
\hline \multicolumn{4}{|l|}{$\begin{array}{l}\text { MEMORY } \\
\text { MODULE(S) }\end{array}$} \\
\hline Vendor & Kingston & Kingston & Samsung \\
\hline Type & DDR & DDR & DDR3 \\
\hline Size & 2GB & 2GB & $2 \mathrm{~GB}$ \\
\hline $\begin{array}{l}\text { Number of RAM } \\
\text { modules }\end{array}$ & $2 \times 1024 \mathrm{MB}$ & $2 \times 1024 M B$ & $2048 \mathrm{MB}$ \\
\hline Channels & Dual & Dual & Single \\
\hline \multicolumn{4}{|l|}{ HARD DISK } \\
\hline $\begin{array}{l}\text { Vendor \& model } \\
\text { numbers }\end{array}$ & Maxtor and 6Y080L0 & Maxtor and 6Y080L0 & $\begin{array}{c}\text { Seagate } \\
\text { ST500DM002- } \\
\text { 1BD142 }\end{array}$ \\
\hline Type & IDE & IDE & SATA \\
\hline Size & $80 \mathrm{~GB}$ & $80 \mathrm{~GB}$ & $500 \mathrm{~GB}$ \\
\hline $\begin{array}{l}\text { Number of Disk in } \\
\text { System }\end{array}$ & 1 & 1 & 1 \\
\hline \multicolumn{4}{|l|}{$\begin{array}{l}\text { OPERATING } \\
\text { SYSTEM }\end{array}$} \\
\hline Name & $\begin{array}{c}\text { Microsoft Windows } 7 \\
\text { (32-bit) }\end{array}$ & $\begin{array}{c}\text { Microsoft Windows } 7 \\
\text { (32-bit) }\end{array}$ & $\begin{array}{c}\text { Microsoft Windows } 7 \\
\text { (64-bit) }\end{array}$ \\
\hline Language & English & English & English \\
\hline
\end{tabular}

\section{RESULTS AND DISCUSSION}

\subsection{Novabench}

The table below shows an average of three-test score of CPU and RAM component for each system configuration: Intel Pentium IV $2.40 \mathrm{GHz}$, Intel Pentium IV $2.80 \mathrm{GHz}$, and Intel Pentium G640T $2.40 \mathrm{GHz}$. 
International Journal of Computer Science \& Information Technology (IJCSIT) Vol 7, No 6, December 2015

Table 2. Novabench Test Score of 2.4 GHz \& 2.8 GHz Single-Core and 2.4 GHz Dual-Core Configurations

\begin{tabular}{|l|l|l|l|}
\hline & $\begin{array}{l}\text { Intel Pentium 4 } \\
\mathbf{2 . 4 0 G H z}\end{array}$ & $\begin{array}{l}\text { Intel Pentium 4 } \\
\mathbf{2 . 8 0 G H z}\end{array}$ & $\begin{array}{l}\text { Intel Pentium } \\
\text { G640T 2.40GHz }\end{array}$ \\
\hline 2040 MB System RAM & Score: 95 & Score: 95 & Score: 112 \\
\hline RAM Speed (MB/s) & 1446 & 1504 & 5215 \\
\hline CPU Tests & Score: 55 & Score: 100 & Score: 229 \\
\hline $\begin{array}{l}\text { Floating Point } \\
\text { Operations/Second }\end{array}$ & 13453050 & 27492557 & 50843295 \\
\hline Integer Operations/Second & 17622214 & 58554955 & 142977614 \\
\hline $\begin{array}{l}\text { MD5 Hashes } \\
\text { Generated/Second }\end{array}$ & 3345501 & 297062 & 794837 \\
\hline
\end{tabular}

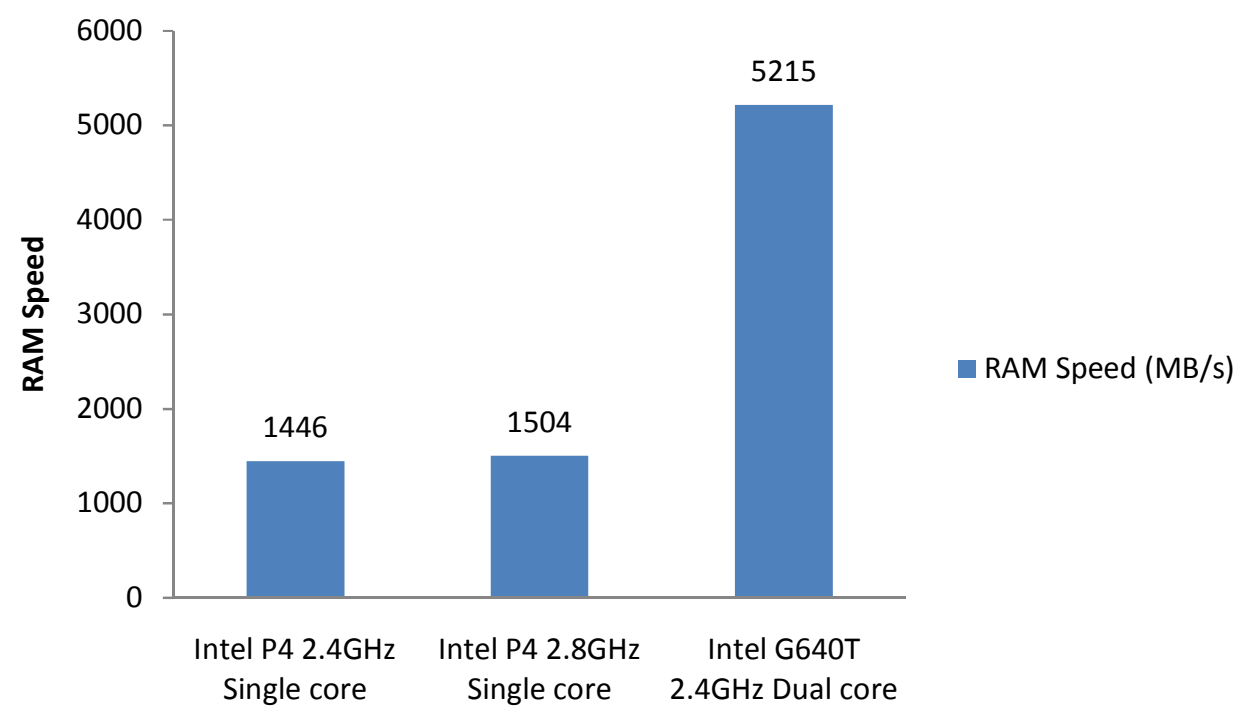

Figure 3. RAM Speed (MB/s) of $2.4 \mathrm{GHz} \& 2.8 \mathrm{GHz}$ Single-Core, and $2.4 \mathrm{GHz}$ Dual-Core 
International Journal of Computer Science \& Information Technology (IJCSIT) Vol 7, No 6, December 2015

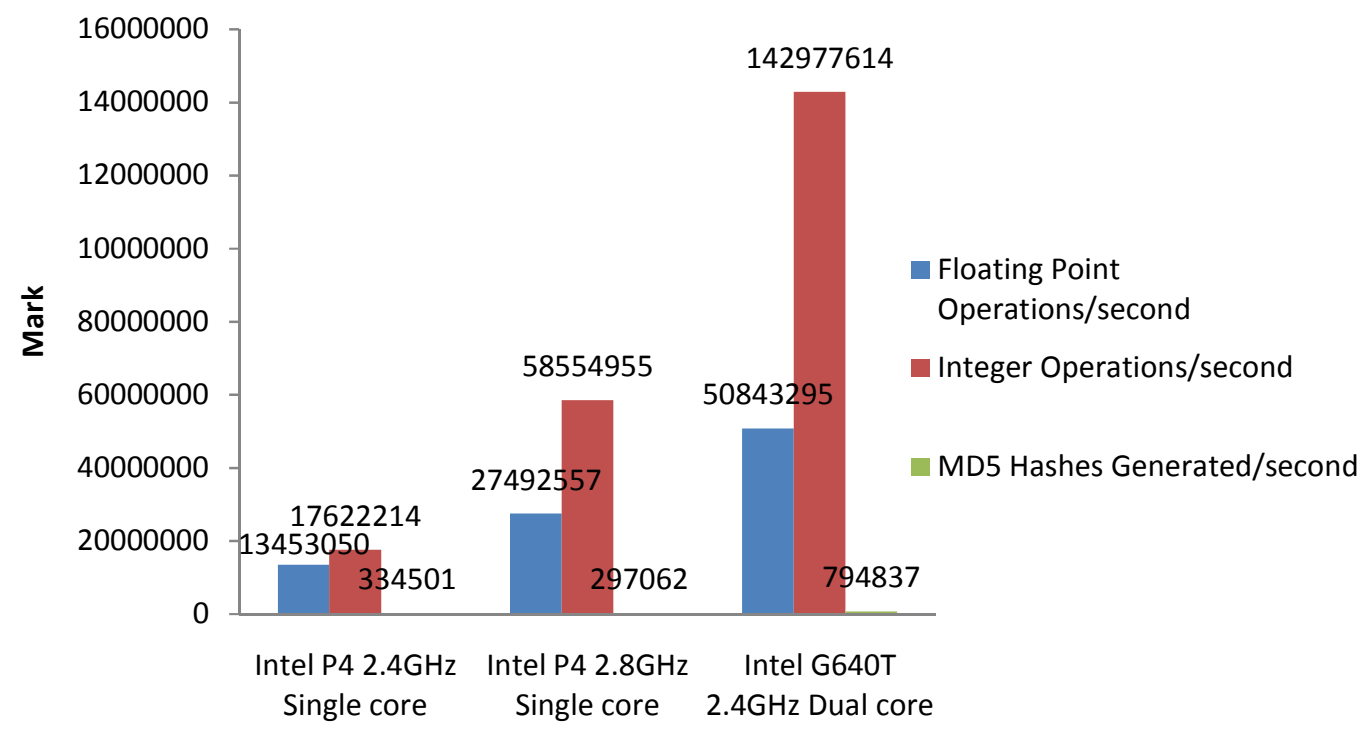

Figure 4. CPU Operations per Second

\subsection{Intelburn Test- Linpack}

Linpack performs an operation from linear algebra called LU Factorization [22]. The three systems under experimental observation are found to be stable.

Table 3. Linpack Result of Intel P4 2.4 GHz Single-Core

\begin{tabular}{|l|l|l|l|}
\hline \multicolumn{4}{|c|}{ Linpack Output Result for Intel Pentium 4 2.40GHz @ 2.394 MHz Single-core } \\
\hline & Time (s) & Speed (GFlops) & Result \\
\hline 1 & 234.925 & 3.8050 & $2.908973 \mathrm{e}-002$ \\
\hline 2 & 233.757 & 3.8240 & $2.908973 \mathrm{e}-002$ \\
\hline 3 & 231.678 & 3.8583 & $2.908973 \mathrm{e}-002$ \\
\hline 4 & 232.552 & 3.8438 & $2.908973 \mathrm{e}-002$ \\
\hline 5 & 232.742 & 3.8407 & $2.908973 \mathrm{e}-002$ \\
\hline 6 & 231.629 & 3.8591 & $2.908973 \mathrm{e}-002$ \\
\hline 7 & 231.814 & 3.8560 & $2.908973 \mathrm{e}-002$ \\
\hline 8 & 231.602 & 3.8596 & $2.908973 \mathrm{e}-002$ \\
\hline 9 & 229.441 & 3.8959 & $2.908973 \mathrm{e}-002$ \\
\hline 10 & 229.924 & 3.8877 & $2.908973 \mathrm{e}-002$ \\
\hline $\begin{array}{l}\text { Test completed successfully in } 2607.47 \text { seconds. } \\
\text { Average GFlops: } 3.85301\end{array}$ \\
\hline
\end{tabular}


Table 4. Linpack Result of Intel P4 2.8 GHz Single-Core

\begin{tabular}{|l|l|l|l|}
\hline \multicolumn{4}{|c|}{ Linpack Output Result for Intel Pentium 4 2.80GHz @ 2.793 MHz Single-core } \\
\hline & Time (s) & Speed (GFlops) & Result \\
\hline 1 & 281.094 & 3.1800 & $3.265950 \mathrm{e}-002$ \\
\hline 2 & 280.838 & 3.1829 & $3.265950 \mathrm{e}-002$ \\
\hline 3 & 284.360 & 3.1435 & $3.265950 \mathrm{e}-002$ \\
\hline 4 & 280.986 & 3.1812 & $3.265950 \mathrm{e}-002$ \\
\hline 5 & 280.581 & 3.1858 & $3.265950 \mathrm{e}-002$ \\
\hline 6 & 280.412 & 3.1878 & $3.265950 \mathrm{e}-002$ \\
\hline 7 & 281.230 & 3.1785 & $3.265950 \mathrm{e}-002$ \\
\hline 8 & 280.596 & 3.1857 & $3.265950 \mathrm{e}-002$ \\
\hline 9 & 280.848 & 3.1828 & $3.265950 \mathrm{e}-002$ \\
\hline 10 & 280.750 & 3.1839 & $3.265950 \mathrm{e}-002$ \\
\hline $\begin{array}{l}\text { Test completed successfully in } 3169.20 \mathrm{~seconds} \\
\text { Average GFlops: } 3.17921\end{array}$ & \\
\hline
\end{tabular}

Table 5. Linpack Result of Intel Pentium G640T 2.4 GHz Dual-Core

\begin{tabular}{|l|l|l|l|}
\hline \multicolumn{5}{|c|}{$\begin{array}{c}\text { core } \\
\text { cinpack Output Result for Intel Pentium G640T 2.4GHz @ 2.394 MHz Dual- }\end{array}$} \\
\hline & Time (s) & Speed (GFlops) & Result \\
\hline 1 & 53.876 & 16.5915 & $3.436777 \mathrm{e}-002$ \\
\hline 2 & 53.087 & 16.8381 & $3.436777 \mathrm{e}-002$ \\
\hline 3 & 53.018 & 16.8600 & $3.436777 \mathrm{e}-002$ \\
\hline 4 & 53.005 & 16.8641 & $3.436777 \mathrm{e}-002$ \\
\hline 5 & 52.935 & 16.8863 & $3.436777 \mathrm{e}-002$ \\
\hline 6 & 52.941 & 16.8844 & $3.436777 \mathrm{e}-002$ \\
\hline 7 & 52.951 & 16.8812 & $3.436777 \mathrm{e}-002$ \\
\hline 8 & 52.929 & 16.8883 & $3.436777 \mathrm{e}-002$ \\
\hline 9 & 52.938 & 16.8855 & $3.436777 \mathrm{e}-002$ \\
\hline 10 & 52.947 & 16.8827 & $3.436777 \mathrm{e}-002$ \\
\hline $\begin{array}{l}\text { Test completed successfully in } 611.98 \text { seconds. } \\
\text { Average GFlops: } 16.84621\end{array}$ \\
\hline
\end{tabular}


International Journal of Computer Science \& Information Technology (IJCSIT) Vol 7, No 6, December 2015

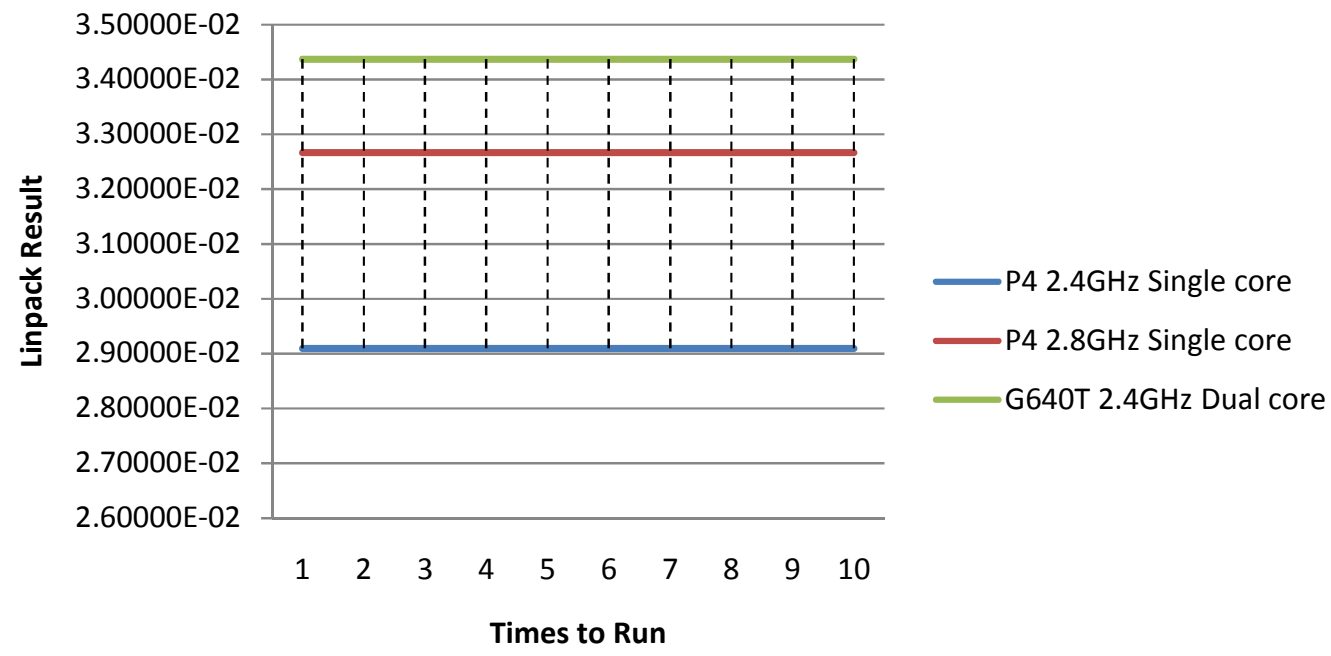

Figure 5. Intel(R) Linpack Output Result for Single-Core and Dual-Core

\subsection{Performance Test}

Table 6. Performance for Pentium IV 2.4 GHz \& 2.8 GHz Single-Core, and 2.4 GHz Dual-Core

\begin{tabular}{|l|l|l|l|}
\hline & $\begin{array}{l}\text { Intel Pentium 4 } \\
\mathbf{2 . 4 0 G H z} @ \mathbf{2 . 4} \mathbf{G H z}\end{array}$ & $\begin{array}{l}\text { Intel Pentium 4 } \\
\mathbf{2 . 8 0 G H z} @ \mathbf{2 . 8} \mathbf{G H z}\end{array}$ & $\begin{array}{l}\text { Intel Pentium } \\
\text { G640T 2.40GHz @ } \\
\mathbf{2 . 4} \mathbf{~ G H z}\end{array}$ \\
\hline CPU Mark & $\mathbf{3 1 7 . 2}$ & $\mathbf{4 5 2 . 0}$ & $\mathbf{2 5 3 1 . 4}$ \\
\hline CPU - Integer Math & 48.1 & 80.6 & 843.4 \\
\hline $\begin{array}{l}\text { CPU - Floating Point } \\
\text { Math }\end{array}$ & 237.8 & 250.1 & 1056.4 \\
\hline $\begin{array}{l}\text { CPU - Find Prime } \\
\text { Numbers }\end{array}$ & 119.9 & 107.3 & 639.6 \\
\hline $\begin{array}{l}\text { CPU - Multimedia } \\
\text { Instructions }\end{array}$ & 0.3 & 0.35 & 8.4 \\
\hline CPU - Compression & 677.0 & 1108.9 & 2803.7 \\
\hline CPU - Encryption & 1.80 & 4.72 & 7.2 \\
\hline CPU - Physics & 23.0 & 31.5 & 143.7 \\
\hline CPU - String Sorting & 401.7 & 541.5 & 1679.4 \\
\hline MEMORY Mark & $\mathbf{3 8 3 . 7}$ & $\mathbf{4 0 9 . 6}$ & $\mathbf{7 9 2 . 3}$ \\
\hline Allocate Small Block & 906.4 & 1238.6 & 4468.9 \\
\hline Read Cached & 1562.9 & 1581.4 & 1920.0 \\
\hline Read Uncached & 1267.9 & 1383.1 & 1778.5 \\
\hline Write & 793.7 & 941.0 & 1730.7 \\
\hline Large RAM & 365.8 & 324.6 & 805.8 \\
\hline
\end{tabular}




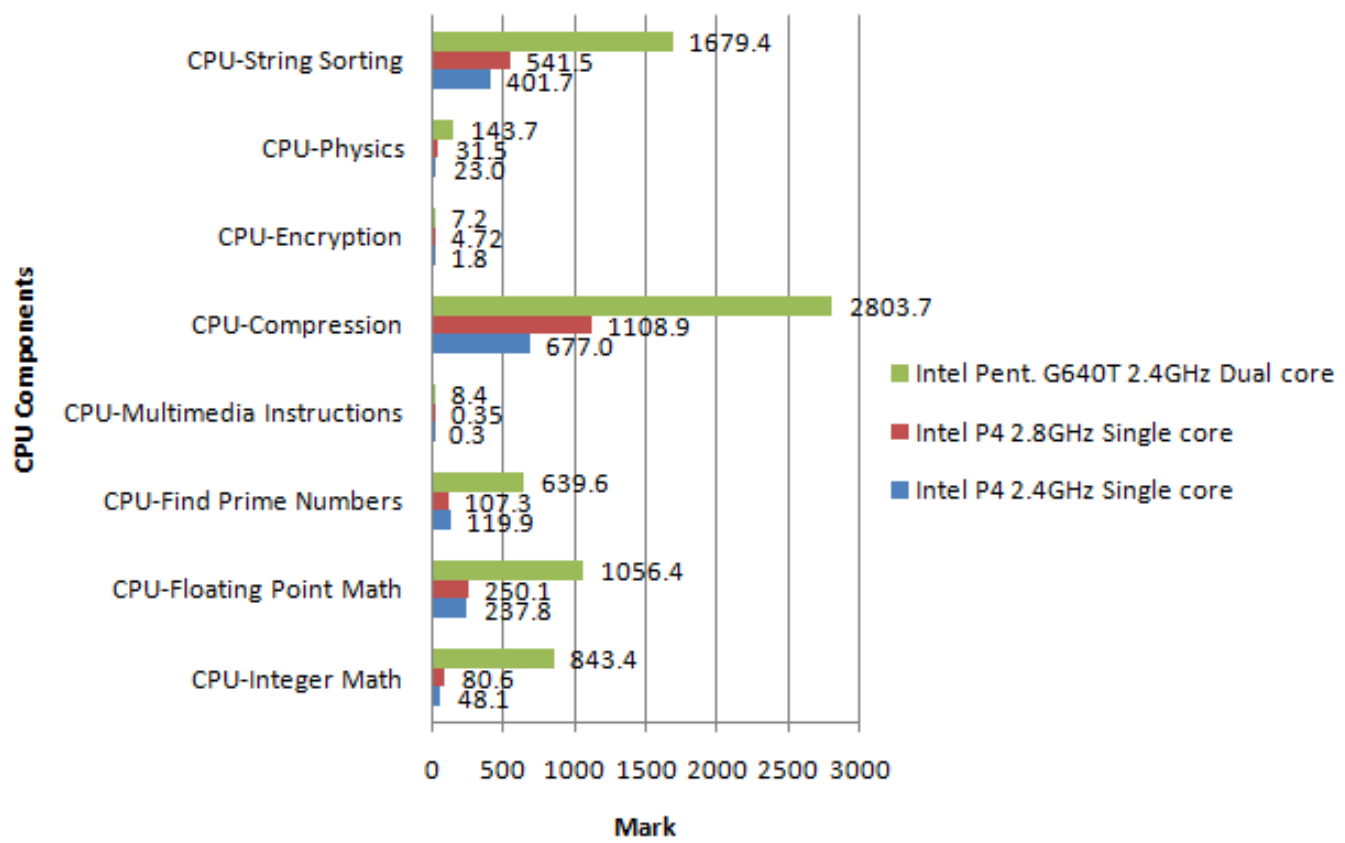

Figure 6. CPU Performance Mark for Single-Core and Dual-Core Systems

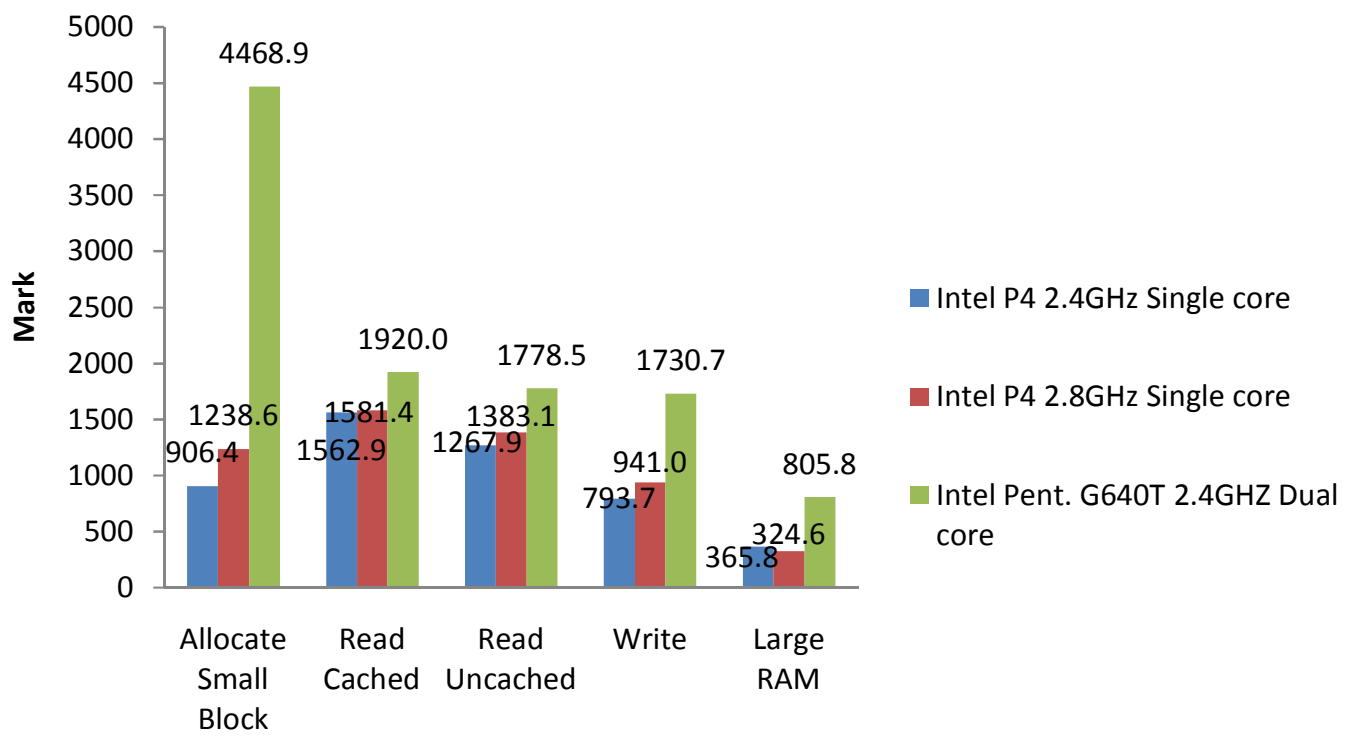

Memory Components

Figure 7. Memory Performance Mark for Single-Core and Dual-Core Systems 
International Journal of Computer Science \& Information Technology (IJCSIT) Vol 7, No 6, December 2015

Table 7. Transfer of 33.3GB File (Copy) from External SATA-HDD to the System

\begin{tabular}{|l|l|l|l|}
\hline & $\begin{array}{l}\text { Intel Pentium 4 } \\
\mathbf{2 . 4 G H z} \text { Single-core }\end{array}$ & $\begin{array}{l}\text { Intel Pentium 4 } \\
\mathbf{2 . 8 G H z} \text { Single-core }\end{array}$ & $\begin{array}{l}\text { Intel Pentium } \\
\text { G640T 2.4GHz } \\
\text { Dual-core }\end{array}$ \\
\hline Number of Processes & 38 & 38 & 38 \\
\hline CPU Usage & $57 \%$ & $40 \%$ & $16 \%$ \\
\hline Physical Memory & $\begin{array}{l}29 \%-30 \% \\
611 \mathrm{MB}-624 \mathrm{MB}\end{array}$ & $\begin{array}{l}32 \%-33 \% \\
620 \mathrm{MB}-650 \mathrm{MB}\end{array}$ & $\begin{array}{l}40 \%-41 \% \\
795 \mathrm{MB}-816 \mathrm{MB}\end{array}$ \\
\hline Maximum Frequency & $100 \%$ & $100 \%$ & $60 \%-69 \%$ \\
\hline $\begin{array}{l}\text { Time Taken to Copy } \\
\text { files }\end{array}$ & 1489 seconds & 1446 seconds & 1284 seconds \\
\hline $\begin{array}{l}\text { CPU Temperature } \\
\text { Before Experiment }\end{array}$ & $38^{\circ} \mathrm{C}$ & $38^{\circ} \mathrm{C}$ & $35^{\circ} \mathrm{C}$ \\
\hline $\begin{array}{l}\text { CPU Temperature } \\
\text { After Experiment }\end{array}$ & $41^{\circ} \mathrm{C}$ & $41^{\circ} \mathrm{C}$ & $39^{\circ} \mathrm{C}$ \\
\hline Core Voltage & $1.470 \mathrm{volts}$ & $1.340 \mathrm{volts}$ & $0.776 \mathrm{volts}$ \\
\hline Maximum TDP & $89 \mathrm{~W}$ & $89 \mathrm{~W}$ & $35 \mathrm{~W}$ \\
\hline
\end{tabular}

Total Execution time of Intel Pentium IV $2.4 \mathrm{GHz}$ Single-core system is 1489 seconds.

Total Execution time of Intel Pentium IV $2.8 \mathrm{GHz}$ Single-core system is 1446 seconds.

Total Execution time of Intel Pentium G640T 2.4 GHz Dual-core system is 1284 seconds.

It is the usual norm to evaluate and relate the performance of two different computers, say, $\mathrm{X}$ and $\mathrm{Y}$. When computer $\mathrm{X}$ is faster than computer $\mathrm{Y}$, this means that the time taken to execute or complete a particular task and/or process on computer $\mathrm{X}$ is lower than on computer $\mathrm{Y}$. Then, computer $\mathrm{X}$ is $\mathrm{n}$ times faster than computer $\mathrm{Y}[21]$.

Therefore,

$$
\begin{aligned}
& \frac{\text { Execution time of } Y}{\text { Execution time of } X}=n \\
& n=\frac{\text { Execution time of } Y}{\text { Execution time of } X}=\frac{\frac{1}{\text { Performance of } Y}}{\frac{1}{\text { Performance of } X}}=\frac{\text { Performance of } X}{\text { Performance of } Y}
\end{aligned}
$$

The most significant approach for measuring performance is by considering the execution time of real programs/process. Performance and execution time are reciprocals, increasing performance decreases execution time [21].

Given,

$$
n=\frac{\text { Execution time of Single core system }(E x)}{\text { Execution time of Dual core system }(E y)}
$$

To calculate the percentage of the system execution time,

$$
\frac{\text { Execution time of Single core system }(E x)}{\text { Execution time of Dual core system }(E y)}=1+\frac{n}{100}
$$


Therefore,

$$
\begin{aligned}
& \frac{\text { Execution time of Single core system }(E x)}{\text { Execution time of Dual core system }(E y)}-1=\frac{n}{100} \text {...... } \\
& n=\frac{\text { Ex(Pentium } 4 \text { Single core system })- \text { Ex(Pentium G640T Dual core system })}{\text { Ey(Pentium G640T Dual core system })} \\
& \times \frac{100}{1}
\end{aligned}
$$

Now to calculate $n$ for the comparison of Intel Pentium IV 2.4GHz Single-core and Intel Pentium G640T 2.4GHz Dual-core:

$$
\begin{aligned}
& n=\frac{1489-1284}{1284} \times \frac{100}{1} . \\
& n=\frac{205 \times 100}{1284}=\frac{20500}{1284} . \\
& n=15.966 \% \ldots \ldots \ldots \ldots \ldots \ldots
\end{aligned}
$$

Then,

$$
\text { SpeedUp }=\frac{1489}{1284}=1.1597
$$

If we repeat steps (3) - (6) for the comparison of Intel Pentium IV $2.8 \mathrm{GHz}$ Single-core and Intel Pentium G640T 2.4GHz Dual-core systems:

$$
\begin{aligned}
& n=\frac{1446-1284}{1284} \times \frac{100}{1} . \\
& n=\frac{162 \times 100}{1284}=\frac{16200}{1284} . \\
& n=12.6168 \% \ldots \ldots \ldots \ldots \ldots
\end{aligned}
$$

Then,

$$
\text { SpeedUp }=\frac{1446}{1284}=1.1262
$$

Both single-core and multi-core systems responded to the test in sequential and exponential manner, thereby showing significant difference in the architectures as regard certain tasks. Components and devices like HDD, DVD-CD writer and graphic adapter were not considered because of reduced-functionality and technology gap between the periods these systems were introduced into the market. However, major emphasis was put into the CPU-components and RAM as they are the most prominent features of computer architecture.

The Novabench test score when examined showed astronomical difference in the performance of RAM speed and CPU components of $2.4 \mathrm{GHz} \& 2.8 \mathrm{GHz}$ single-core, and $2.4 \mathrm{GHz}$ dual-core respectively. The techno-architecture of single-core processor is one major factor responsible for reduced functionality being experienced while carrying out this research. The chart representation can be found in figure $3 \& 4$.

The dual-core system further exhibit significant superiority over single-core when put under performance benchmark 7.0, the CPU and memory marks shows that the components of the dualcore system is well utilized and of high performance rating. The mark is available in figure 6 and 7 respectively. 
The above results confirm that Intel Pentium G640T 2.4GHz Dual-core system is over $15.97 \%$ faster than Intel Pentium IV 2.4GHz Single-core system and $12.62 \%$ faster than Intel Pentium IV $2.8 \mathrm{GHz}$ Single-core system during the transfer of $33.3 \mathrm{~GB}$ files from external HDD to these systems, with the speedup of 1.16 and 1.13 respectively. This is however synonymous to one of the various methods of comparing Single-core and Multi-core (Dual-core) systems [22], an explanation well-understood by an ordinary user; and in all cases of such and others the performance of multi-core will always surpass single-core except for single-threaded applications. Also, the table above shows the CPU Usage of $57 \%$ and $40 \%$ for Pentium IV $2.4 \mathrm{GHz}$ and 2.8GHz Single-core at Maximum Frequency $100 \%$, this explains great differences between Single-core and Multi-core because at Maximum Frequency the systems were heat up and any attempt to perform additional operation (multitask) will drag the systems and if further intensify will breakdown the systems; in fact rendering could not be attempted because of reducedfunctionality in Single-core. The Physical Memory result shows that there is a limit to what memory could do when the frequency is 100 percent utilized as we saw in the experiment. But this is not the case of Pentium G640T Dual-core as the CPU Usage was just 16\%, Maximum Frequency 60\% - 69\% and Physical Memory 795MB - 816MB.

With all the astronomical performance display by dual-core in all test, one would have expected a faster rating and clear-cut speed when copying from an external HDD to the system, but this was not so as the time difference between the dual-core and single-core was not large; however, this is the peak of Intel Pentium IV $2.4 \mathrm{GHz}$ and $2.8 \mathrm{GHz}$ performance because the frequency was totally exhausted, temperature rising fast, and core voltage increasing thereby demanding more power. Therefore, the study envisages that communication overhead and memory latencies are still a limiting factor in multi-core performance. Finding good cache configurations would be helpful, thereby taking pressure off the main memory and reducing communication and cache coherence latencies, and increasing overall performance [23].

Linpack experiment clearly showed that all the systems being considered were stable and had operational capacity; the time taken to complete the looping for each system and the average GFLOPs obtained put Intel Pentium G640T 2.4GHz dual-core ahead of Intel Pentium IV 2.4GHz $\& 2.8 \mathrm{GHz}$ single-core, which comply with international benchmark. In all the test dual-core components had better rating, the linpack stress test was completed in 611.98 seconds with average GFLOPs 16.85 as against Intel Pentium IV $2.4 \mathrm{GHz}$ and $2.8 \mathrm{GHz}$ single-core systems which was completed in 2607.47 and 3169.20 seconds, and GFLOPs 3.85 and 3.18 respectively. Why the GFLOPs of Pentium IV $2.4 \mathrm{GHz}$ surpassed its $2.8 \mathrm{GHz}$ counterpart could not be ascertained as at the time of compiling this research. Intel Pentium G640T 2.4GHz dual-cores, unlike the single-core processors has maximum TDP of $35 \mathrm{~W}$, which makes it a low power consumption processor. It also utilizes the RAM memory more efficiently than the single-core, which necessitated the hypothesis that CPU architecture determines the limit of RAM utilization in a system and can not be stretched beyond this limit.

\section{CONCLUSION}

The study was able to show that G640T dual-core was $15.97 \%$ and $12.62 \%$ faster than Pentium IV $2.4 \mathrm{GHz}$ and $2.8 \mathrm{GHz}$ single-cores during the file transfer process, with the speedup of 1.16 and 1.13 respectively. The CPU usage for Pentium IV $2.4 \mathrm{GHz}$ and $2.8 \mathrm{GHz}$ were $57 \%$ and $40 \%$ at peak frequency while 16\% CPU usage was observed in G640T dual-core; Novabench and Performance Test of CPU and Memory components rates G640T dual-core far above the singlecore(s). After all investigation the research concludes that the success of multi-core so far can not be derived from its clock speed when placed side-by-side a single-core of same clock speed or higher but division of labour amongst cores, faster core-to-core communication, dynamic cache sharing between cores, smaller size of caches, lower core and bus frequencies, with significant 
contribution from the memory as shown in the linpack experiment (average GFLOPs- 16.85), and the time taken to successfully complete ten loops (i.e. 611.98 second); this is the major reason they perform well in multi-threaded application and could not replicate the performance in singlethreaded application.

This study points out the fact that despite the effectiveness and efficiency associated with multicore system as against single-core system, which emanated as a result of technological advancement and architectural redesign, it still has certain deficiencies that must be overcome for optimal overall performance while the single-core which provided the need for more cores is still good and reliable for specific purposes.

\section{RECOMMENDATION}

Though single-core has made a mark and multi-core is taking over, increasing the frequency by all means and reducing the power at all cost in proportion to the core(s) of a processor is not the real solution to the problems facing multi-core but the need to channel more resources into coming up with better architectural design that would hasten synchronization between cores and memory, and relinquish unnecessary on-chip interconnect delay, latency \& cache issue, and indecision that contributes to unwarranted slow pace of performance in multi-core processors.

\section{REFERENCES}

[1] Cass, S. (2010). Multicore Processors Create Software Headaches. Technology Review, 113(3), 7475.

[2] Parkhurst, J., Darringer, J. \& Grundmann, B. (2006). From Single Core to Multi-Core: Preparing for a new exponential, Computer-Aided Design. ICCAD '06. IEEE/ACM International Conference on, pp. 67.

[3] Goodacre, J. \& Sloss, A.N. (2005). Parallelism and the ARM instruction set architecture, Computer, vol. 38, no. 7, pp. 42-50.

[4] Michael R. Marty, (2008). Cache Coherence Techniques for Multicore Processors.

[5] V. Agarwal, M. S. Hrishikesh, S. W. Keckler, \& D. Burger, (2000). Clock Rate versus IPC: The End of the Road for Conventional Microarchitectures. In Proceedings of the 27th Annual International Symposium on Computer Architecture, pages 248-259.

[6] Lizhe Wang, Jie Tao, Gregor von Laszewski, Holger Marten. (2010). Multicores in Cloud Computing: Research Challenges for Applications. Journal of Computers, Vol 5, No 6.

[7] Carlos Madriles, Pedro López, Josep M. Codina, Enric Gibert, Fernando Latorre, Alejandro Martínez, Raúl Martínez and Antonio González (2009). Boosting Single-thread Performance in Multi-core Systems through Fine-Grain Multi-Threading. Intel Barcelona Research Center, Intel Labs. Universitat Politècnica de Catalunya, Barcelona (Spain).

[8] D. Geer, (2005). Chip Makers Turn to Multicore Processors. Computer, vol. 38, pp. 11-13.

[9] Balaji Venu (2011). Multi-core processors: An overview. Department of Electrical Engineering and Electronics, University of Liverpool, Liverpool, UK.

[10] H. Lance, N. A. Basem, \& O. Kunle (1997). A Single-Chip Multiprocessor. IEEE Computer, Volume: 30 , Issue: 9 , pp.79-85.

[11] Pollawat Thanarungroj, \& Chen Liu. Power and Energy Consumption Analysis on Intel SCC ManyCore System

[12] Thomas Moscibroda Onur Mutlu (2007). Memory Performance Attacks: Denial of Memory Service in Multi-Core Systems. Microsoft Research.

[13] Kalyani D. Kolhe, U. M. Gokhale, Darshan Pendhari (2014). Design of Cache Controller for Multicore Systems Using Parallelization Method. Proceedings of 11th IRF International Conference, 15th June-2014, Pune, India, ISBN: 978-93-84209-27-8.

[14] Jongman Kim, Dongkook Park, Theocharides, T., Vijaykrishnan, N. \& Das, C.R. (2005). A low latency router supporting adaptivity for on-chip interconnects. Design Automation Conference. Proceedings. 42nd, pp. 559 
[15] Y. Hoskote, S. Vangal, A. Singh, N. Borkar and S. Borkar, (2007). A 5-GHz Mesh Interconnect for a Teraflops Processor. Micro, IEEE, vol. 27, pp. 51-61.

[16] Moore, S.K. (2008). Multicore is bad news for supercomputers. Spectrum, IEEE, vol. 45, no. 11, pp. $15-15$.

[17] A.I. Fasiku, J. B. Olawale, O. T. Jinadu (2012). A Review of Architectures - Intel Single Core, Intel Dual Core and AMD Dual Core Processors and the Benefits. International Journal of Engineering and Technology Volume 2 No. 5.

[18] V. Saxena and M. Shrivastava, (2009). UML Modeling and Performance Evaluation of Multithreaded Programs on Dual Core Processor. Ambedkar University (Central University), Lucknow, India, published by International Journal of Hybrid Information Technology Vol.2, No.3.

[19] Vipin S. Bhure, Praveen R. Chakole. Design of Cache Controller for Multi-core Processor System. International Journal of Electronics and Computer Science Engineering. Available Online at www.ijecse.org ISSN-2277-1956/V1N2-520-526

[20] Hongtao Zhong (2008). Architectural and Compiler Mechanisms for Accelerating Single Thread Applications on Multicore Processors. A dissertation submitted in partial fulfilment of the requirements for the degree of Doctor of Philosophy (Computer Science and Engineering) in The University of Michigan.

[21] Fasiku, A. Ireti, Olawale, J. Babatunde, \& Abiola, B. Oluwatoyin, (2013). Comparison of Intel Single-Core and Intel Dual-Core Processor Performance. International Journal of Scientific Research in Computer Science and Engineering, www.isroset.org, Volume-1, Issue-1.

[22] Douglas M. Pase and Matthew A. Eckl (2005). A Comparison of Single-Core and Dual-Core Opteron Processor Performance for HPC. IBM xSeries. Performance Development and Analysis 3039 Cornwallis Rd. Research Triangle Park, NC 27709-2195.

[23] Julian Bui, Chenguang Xu, and Sudhanva Gurumurthi (2007). Understanding Performance Issues on both Single Core and Multi-core Architecture.

[24] Scott Schneider (2010). Shared Memory Abstractions for Heterogeneous Multicore Processors. Dissertation submitted to the Faculty of the Virginia Polytechnic Institute and State University in partial fulfilment of the requirements for the degree of Doctor of Philosophy in Computer Science.

[25] Vipin S. Bhure, and Praveen R. Chakole (2012). Design of Cache Controller for Multi-core Processor System. International Journal of Electronics and Computer Science Engineering. Vol.1 N2-520-526. Available Online at www.ijecse.org

[26] Cameron Hughes, and Tracey Hughes. Professional Multicore Programming- Design \& Implementation for C++ Developers. www.wrox.com

[27] https://en.wikipedia.org/wiki/Stress_test_(hardware)

[28] http://forum.sysprofile.de/computerfragen/256129-top-oder-flop-pc.html

\section{AUTHORS}

Ogundairo Johnson graduated from Yaba College of Technology, Yaba, Lagos with Ordinary National Diploma, OND and Higher National Diploma, HND in Electrical and Electronics Engineering. He has also attended National Open University of Nigeria (NOUN), Enugu Campus, Enugu from 2011 to 2013 for both the Postgraduate Diploma and Master of Science degree in Information Technology.

Omosehinmi Dinyo attended Obafemi Awolowo University, Ile-Ife, Nigeria where he was awarded Bachelor of Science degree in Physics. He earned a Master's degree in Physics from the Federal University of Technology, Akure, Nigeria between 2012 and 2015. Dinyo has also obtained certificates in Computer Hardware Engineering, and Radio Network Planning \& Optimization, RNPO.
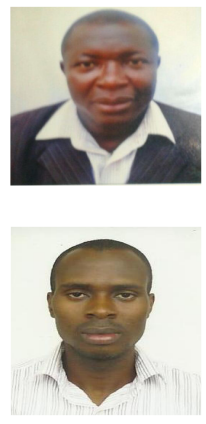